\title{
Standing Posture at Work Does Not Increase the Risk of Varicose Veins among Health Care Providers in Taiwan
}

\author{
Hsin-Kai Huang ${ }^{b}$ Shih-Feng Weng ${ }^{a}$ Shih-Bin Su ${ }^{c, d, g} \quad$ Jhi-Joung Wang ${ }^{d}$ \\ How-Ran Guo ${ }^{j, k}$ Chien-Chin Hsu ${ }^{e, h}$ Chien-Cheng Huang ${ }^{c, e, f, i, j}$ \\ Hung-Jung Lin $^{\mathrm{e}, \mathrm{h}, \mathrm{l}}$ \\ a Department of Healthcare Administration and Medical Informatics, Kaohsiung Medical University, Kaohsiung, \\ ${ }^{b}$ Holistic Care Unit and Departments of ${ }^{c}$ Occupational Medicine, ${ }^{d}$ Medical Research, ${ }^{e}$ Emergency Medicine, \\ and ${ }^{\mathrm{f}}$ Geriatrics and Gerontology, Chi-Mei Medical Center, Departments of ${ }^{\mathrm{L}}$ Leisure, Recreation, and Tourism

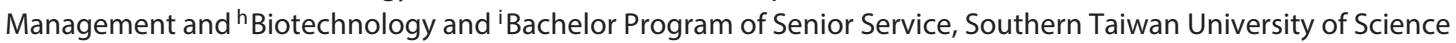 \\ and Technology, 'Department of Environmental and Occupational Health, College of Medicine, National Cheng \\ Kung University, and kDepartment of Occupational and Environmental Medicine, National Cheng Kung University \\ Hospital, Tainan, and 'Department of Emergency Medicine, Taipei Medical University, Taipei, Taiwan
}

\section{Significance of the Study}

- In this study, the cumulative varicose vein (VV) incidence of physicians, nonphysician health care providers, and the general population was $0.12,0.13$, and $0.13 \%$, respectively, during the 5 -year period.

- The VV risk among physician specialists was not different.

- Surgery had the highest incidence $(0.22 \%)$ while pediatrics and emergency medicine had the lowest incidence $(0 \%)$ of VV risk among physician specialists.

\section{Keywords}

Health care provider · Physician · Standing · Specialty ·

varicose vein

\begin{abstract}
Objective: This study compared the risk of varicose veins (VV) among physicians, nonphysician health care providers (HCP), and the general population. Subjects and Methods: The Taiwan National Health Insurance Research Database was used to identify 28,844 physicians and 26,099 nonphysi-
\end{abstract}

\begin{tabular}{ll}
\hline KARGER & ( 2017 S. Karger AG, Basel \\
$\begin{array}{l}\text { E-Mail karger@karger.com } \\
\text { www.karger.com/mpp }\end{array}$ & $\begin{array}{l}\text { This is an Open Access article licensed under the terms of the } \\
\text { Creative Commons Attribution-NonCommercial 3.0 Un- } \\
\text { ported license (CC BY-NC) (www.karger.com/OA-license), } \\
\text { applicable to the online version of the article only. Distribu- } \\
\text { tion permitted for non-commercial purposes only. }\end{array}$
\end{tabular}

cian HCP and an identical number of age- and sex-matched patients from the general population. Using logistic regression analyses, VV risks between physicians and the general population, nonphysician HCP and the general population, and physicians and nonphysician HCP, and among physician specialists were compared by tracing their medical histories between 2007 and 2011. Results: Physicians and nonphysician HCP had cumulative VV incidences of $0.12 \%(34 / 28,844)$ and $0.13 \%(33 / 26,099)$, respectively, during the 5 -year period, compared to that of the general population within the same 5-year period. Physicians and nonphysician HCP did

Chien-Cheng Huang, MD

Department of Emergency Medicine, Chi-Mei Medical Center 901 Zhonghua Road

Yongkang District, Tainan 710 (Taiwan)

E-Mail chienchenghuang@yahoo.com.tw 
not have a higher $V \mathrm{~V}$ risk than the general population after adjusting for deep vein thrombosis (DVT) history (adjusted odds ratio $[A O R] 0.86 ; 95 \%$ confidence interval $[\mathrm{Cl}]$ 0.53-1.40, and AOR $1.43 ; 95 \% \mathrm{Cl} 0.82-2.50$, respectively). Physicians did not a have higher VV risk than nonphysician HCP (AOR 0.80; $95 \% \mathrm{Cl} 0.43-1.51$ ) after adjusting for age, sex, and DVT history. Surgery had the highest incidence $(0.22 \%)$ while pediatrics and emergency medicine had the lowest incidence (0\%) of VV risk among physician specialists; however, the difference was not significant (all $p$ values $>0.05$ ). Conclusion: In this study, VV risk did not differ among physicians, nonphysician HCP, and the general population.

(c) 2017 S. Karger AG, Basel

\section{Introduction}

Varicose veins (VV) of the lower extremities are dilated, palpable, subcutaneous veins with a diameter of more than 3-4 $\mathrm{mm}[1,2]$, and they are classified as class $\mathrm{C} 2$ among chronic venous diseases $[1,2]$. In addition to $\mathrm{VV}$, chronic venous diseases have other clinical manifestations such as telangiectasias, swelling, pigmentation, lipodermatosclerosis, and ulcer [1]. A descriptive clinical, etiological, anatomical, and pathophysiological classification provides an orderly framework for communication and decision making [1]. The pathogenesis of VV involves valve incompetence and venous wall dilation due to venous hypertension $[2,3]$. The Framingham Study reported that the annual incidence of VV was $2.6 \%$ among women and $1.9 \%$ among men in the USA $[1,4]$. VV are more prevalent in populations of European origin than in those of African origin or Asians [1, 5]. The risk factors for VV are age, family history, female sex, obesity, prolonged standing or walking, pregnancy, parity, deep vein thrombosis (DVT), surgery of the lower limbs, and a greater height $[1,6-13]$.

Prolonged standing or walking due to occupational exposure has been suggested to be a cause of VV $[2,11$, 12 ]. In a longitudinal study with a large sample size in Denmark, workers who stood or walked for $6-7.3 \mathrm{~h}$ had a significantly higher risk of surgery of $\mathrm{VV}$ than workers who stood or worked for less than $4 \mathrm{~h}$ (adjusted hazard ratio 3.17 in men and 2.34 in women) [2]. In a study assessing VV risk among hairdressers, the monthly work involved 261-360 standing hours and had an odds ratio (OR) of 31.8 (95\% confidence interval [CI] 25-120) [12]. In Taiwan, physicians have a heavy workload, with long working hours since the launch of the National Health Insurance (NHI) in 1995, which provides easy and equal

Varicose Veins among Health Care Providers

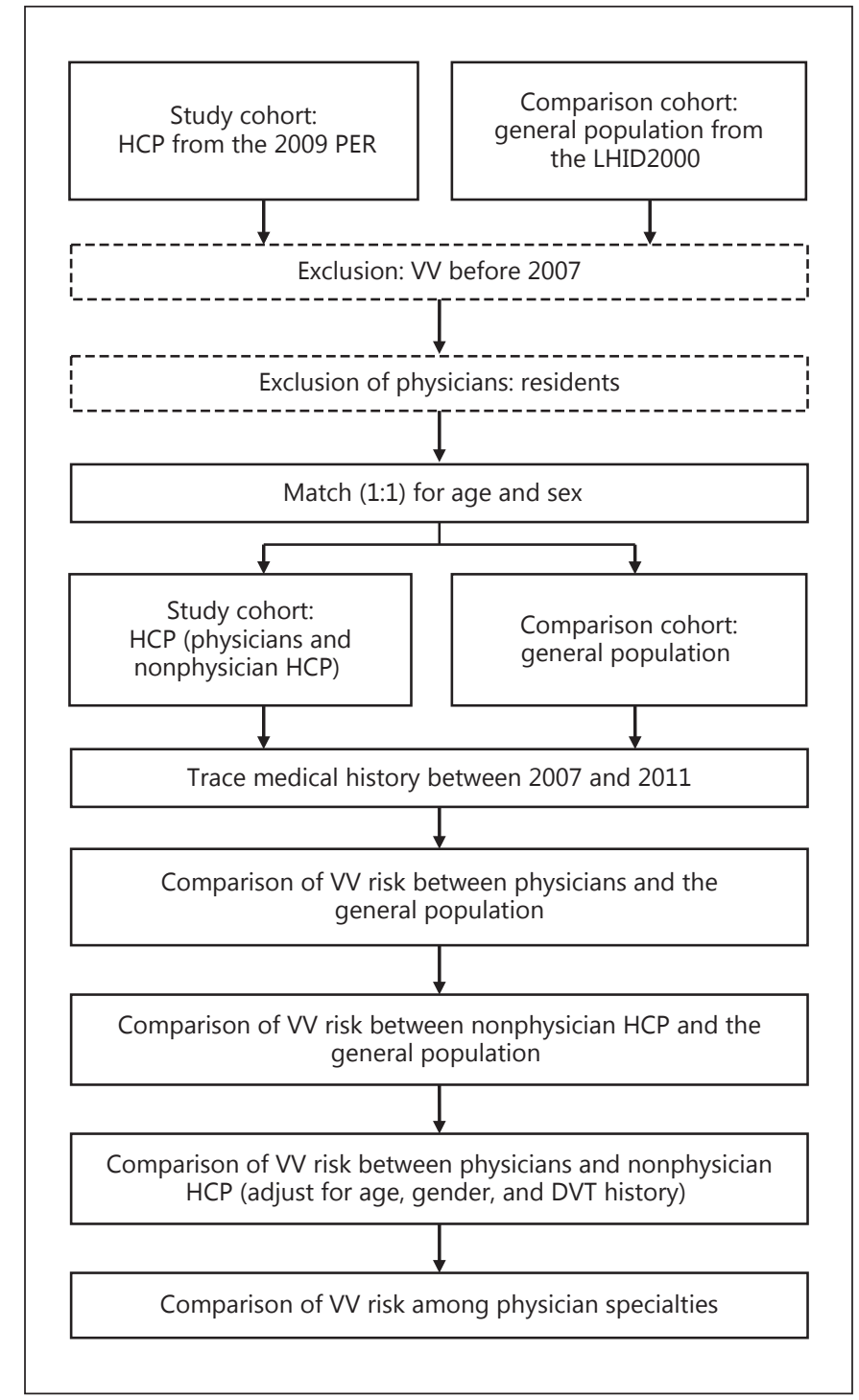

Fig. 1. Flowchart of this study. HCP, health care provider; LHID2000, Longitudinal Health Insurance Database 2000; VV, varicose vein; DVT, deep venous thrombosis; PER, Registry for Medical Personnel.

access to health care to all the citizens [14-16]. More than half of the attending physicians have to work for more than $262.4 \mathrm{~h} /$ month [17]. In certain specialties, physicians have to work for an average of $315.6 \mathrm{~h} /$ month [17]. Long working hours that involve standing or walking could contribute to an increased VV risk [12]. Current$\mathrm{ly}$, there is no available publication comparing VV risk among physicians, nonphysician health care providers (HCP), and the general population. Hence, this study was conducted to clarify this issue.

Med Princ Pract 2017;26:266-272 267 
Table 1. Demographic characteristics and comorbidities of physicians, nonphysician HCP, and the general population

\begin{tabular}{|c|c|c|c|c|c|c|}
\hline Characteristics & $\begin{array}{l}\text { Physicians } \\
(n=28,844)\end{array}$ & $\begin{array}{l}\text { General population } \\
(n=28,844)\end{array}$ & $p$ value & $\begin{array}{l}\text { Nonphysician HCP } \\
(n=26,099)\end{array}$ & $\begin{array}{l}\text { General population } \\
(n=26,099)\end{array}$ & $p$ value \\
\hline Age, years & $46.83 \pm 10.72$ & $46.83 \pm 10.72$ & $>0.999$ & $33.97 \pm 8.41$ & $33.97 \pm 8.41$ & $>0.999$ \\
\hline $\begin{array}{l}\text { Age, years } \\
<35 \\
35-64 \\
\geq 65\end{array}$ & $\begin{array}{r}3,608(12.51) \\
23,418(81.19) \\
1,818(6.30)\end{array}$ & $\begin{array}{r}3,608(12.51) \\
23,418(81.19) \\
1,818(6.30)\end{array}$ & $>0.999$ & $\begin{array}{c}15,754(60.36) \\
10,277(39.38) \\
68(0.26)\end{array}$ & $\begin{array}{c}15,754(60.36) \\
10,277(39.38) \\
68(0.26)\end{array}$ & $>0.999$ \\
\hline $\begin{array}{l}\text { Sex } \\
\text { Male } \\
\text { Female }\end{array}$ & $\begin{array}{r}24,802(85.99) \\
4,042(14.01)\end{array}$ & $\begin{array}{r}24,802(85.99) \\
4,042(14.01)\end{array}$ & $>0.999$ & $\begin{array}{r}7,984(30.59) \\
18,115(69.41)\end{array}$ & $\begin{array}{r}7,984(30.59) \\
18,115(69.41)\end{array}$ & $>0.999$ \\
\hline $\begin{array}{l}\text { Comorbidity } \\
\text { HTN } \\
\text { DM } \\
\text { Hyperlipidemia } \\
\text { DVT history }\end{array}$ & $\begin{array}{c}6,820(23.64) \\
2,343(8.12) \\
6,169(21.39) \\
\quad 35(0.12)\end{array}$ & $\begin{array}{c}5,509(19.10) \\
2,730(9.46) \\
3,733(12.94) \\
\quad 32(0.11)\end{array}$ & $\begin{array}{r}<0.001 \\
<0.001 \\
<0.001 \\
0.714\end{array}$ & $\begin{array}{r}1,511(5.79) \\
532(2.04) \\
1,573(6.03) \\
12(0.05)\end{array}$ & $\begin{array}{r}1,297(4.97) \\
671(2.57) \\
1,009(3.87) \\
9(0.03)\end{array}$ & $\begin{array}{r}<0.001 \\
<0.001 \\
<0.001 \\
0.513\end{array}$ \\
\hline $\begin{array}{l}\text { Living area } \\
\text { North } \\
\text { Center } \\
\text { South } \\
\text { East }\end{array}$ & $\begin{array}{r}13,492(46.78) \\
5,723(19.84) \\
8,871(30.76) \\
758(2.63)\end{array}$ & $\begin{array}{r}14,768(51.20) \\
5,072(17.58) \\
8,371(29.02) \\
633(2.19)\end{array}$ & $<0.001$ & $\begin{array}{r}12,541(48.05) \\
5,063(19.40) \\
7,833(30.01) \\
662(2.54)\end{array}$ & $\begin{array}{r}14,484(55.50) \\
4,492(17.21) \\
6,668(25.55) \\
455(1.74)\end{array}$ & $<0.001$ \\
\hline
\end{tabular}

Values are presented as means \pm SD or $n(\%)$ unless otherwise stated. HCP, healthcare providers; HTN, hypertension; DM, diabetes mellitus; DVT, deep vein thrombosis.

\section{Materials and Methods}

\section{Data Source}

Taiwan launched a single-payer NHI program in 1995. As of $2014,99.9 \%$ of Taiwan's population was enrolled [18]. The NHI Research Database (NHIRD) contains registration files and original claim data for reimbursement, which can be provided to scientists in Taiwan for research purposes [18]. It provides the patient identification number, age, sex, date of visit, length of hospitalization, prescribed medication, treatment, and diagnoses using the International Classification of Diseases, 9th Revision, Clinical Modification (ICD-9-CM) $[15,18]$. The registration files of HCP obtained from the Registry of Medical Personnel (PER) of the NHIRD include residence area, hospital level, type of employment, specialty, date of HCP license, and encrypted identification number (Fig. 1). The general population was recruited from the Longitudinal Health Insurance Database 2000 (LHID2000), which is a data subset of the NHIRD that contains all of the data of 1,000,000 $(4.34 \%$ of the total population) random beneficiaries $[15,18]$.

\section{Selection of the Study Cohort and the Comparison Cohort}

(General Population)

A retrospective cohort study was conceived based on the NHIRD, which contains all of the disease diagnoses and data for reimbursement of $99.9 \%$ of Taiwan's population since 1995 . Because the NHIRD has a comprehensive and prospectively collected database, it is a good choice for a retrospective cohort study. The
NHIRD was reviewed to identify physicians and nonphysician HCP (study cohort) from the 2009 PER (Fig. 1). The general population (comparison cohort) was identified from the LHID2000 (Fig. 1). Nonphysician HCP included technicians, rehabilitation therapists, audiologists, and social workers. The VV risk of nonphysician HCP was compared with that of physicians to evaluate the healthy-worker effect. Exclusion criteria were: having a history of VV (ICD-9-CM: 454) before 2007 and being a resident. Residents were excluded because they usually had rotating training specialties and insufficient experience. The HCP and the general population were matched at a 1:1 ratio for age and sex. Included in the analysis were comorbidities such as hypertension (ICD-9CM: 401-405), diabetes mellitus (ICD-9-CM: 250), hyperlipidemia (ICD-9-CM: 272), DVT history (ICD-9-CM: 453.40), and living areas.

This study was approved by the Chi-Mei Medical Center Institutional Review Board and complied with the ethics principles of the Declaration of Helsinki. The Institutional Review Board waived the need for informed consent because the NHIRD consists of deidentified information for academic research. The patients' rights and welfare were unaffected.

Comparison between Physicians and Nonphysicians and among Physician Specialists

A total of 28,844 physicians and 26,099 nonphysician HCP and an identical number of patients from the general population (after being matched by age and sex) were identified (Table 1). Their 
Table 2. Comparison of VV risk between physicians and the general population by conditional logistic regression

\begin{tabular}{llll}
\hline & $n(\%)$ & OR $(95 \% \mathrm{CI})$ & AOR $(95 \% \mathrm{CI})^{\mathrm{a}}$ \\
\hline $\begin{array}{l}\text { Overall analysis } \\
\text { Physicians } n=28,844)\end{array}$ & $34(0.12)$ & $0.92(0.58-1.46)$ & $0.86(0.53-1.40)$ \\
General population $(n=28,844)$ & $37(0.13)$ & 1.00 & 1.00 \\
\hline Stratified analysis & & & \\
Age $<35$ years & & $2.00(0.18-22.06)$ & $2.00(0.18-22.06)$ \\
$\quad$ Physicians & $2(0.06)$ & 1.00 & 1.00 \\
$\quad 1(0.03)$ & & $1.00(0.59-1.69)$ & $0.93(0.54-1.58)$ \\
General population & $28(0.12)$ & 1.00 & 1.00 \\
$\quad 28(0.12)$ & & $0.29(0.06-1.38)$ \\
$\quad$ Physicians & $4(0.22)$ & 1.00 & 1.00 \\
$\quad$ General population & $8(0.44)$ & $1.14(0.69-1.9)$ & $1.08(0.63-1.84)$ \\
Age $\geq 65$ years & & & 1.00 \\
$\quad$ Physicians & $32(0.13)$ & 1.00 & $0.22(0.05-1.03)$ \\
$\quad$ General population & $28(0.11)$ & $0.22(0.05-1.03)$ & 1.00 \\
Male & & 1.00 &
\end{tabular}

$\mathrm{CI}$, confidence interval; VV, varicose vein; OR, odds ratio; AOR, adjusted odds ratio; DVT, deep vein thrombosis. ${ }^{a}$ Adjusted for DVT history.

medical history was traced from 2006 to 2011 to compare VV risk by cumulative incidence between HCP and the general population. Stratified analyses by age and sex were also performed. VV risk was compared between physicians and nonphysician HCP and among physician specialists, including 8 specialties: surgery, internal medicine, pediatrics, obstetrics and gynecology, emergency medicine, family medicine, dual specialists (e.g., a physician who has boards of both internal medicine and emergency medicine), and others. The comparison was performed among specialists because different specialists have different working hours that might contribute to the difference in VV risk.

\section{Statistical Analyses}

Student's $t$ test (for continuous variables) and a $\chi^{2}$ test (for categorical variables) were used to compare the differences among the demographic data, comorbidities, and living areas between HCP and the general population. Conditional logistic regression was used to compare VV risk between physicians and the general population and between nonphysician HCP and the general population after adjusting for DVT history, which was the only available and probable confounding factor in addition to age and sex in our study. Unconditional logistic regression was used to compare VV risk between physicians and nonphysician HCP and among physician specialists after adjusting for age, sex, and DVT history. SAS 9.3.1 for Windows (SAS Institute, Cary, NC, USA) was used for all analyses. $p<0.05$ (2-tailed) was considered statistically significant.

Varicose Veins among Health Care Providers

\section{Results}

The number of physicians and nonphysician HCP identified was 28,844 and 26,099 , respectively. The number of individuals from the general population from the LHID2000 was 28,844 . The mean age of the physicians and nonphysician HCP was $46.83 \pm 10.72$ and $33.97 \pm$ 8.41 years, respectively (Table 1 ). The mean age of the general population matched with physicians and nonphysician HCP was $46.83 \pm 10.72$ and $33.97 \pm 8.41$ years, respectively. Of the 28,844 physicians and 26,099 nonphysician HCP, 27,026 (94\%) and 26,031 (99.7\%) were in the age subgroup of $35-64$ years and $<35$ years, respectively. Also, of the 28,844 physicians 24,802 (86\%) were men, and of the 26,099 nonphysician HCP 18,115 (69.41\%) were women. HCP including physicians and nonphysician HCP had a higher prevalence of hypertension (i.e., 23.64 and 19.10\%, respectively) and hyperlipidemia (i.e., 21.39 and $6.03 \%$, respectively) but a lower prevalence of diabetes mellitus (i.e., 8.12 and 2.04\%, respectively) than the general population. There was no significant difference in DVT history between HCP and the general population (physicians vs. the general popula-

Med Princ Pract 2017;26:266-272 269 
Table 3. Comparison of VV risk between nonphysician HCP and the general population by conditional logistic regression

\begin{tabular}{llll}
\hline & $n(\%)$ & OR $(95 \% \mathrm{CI})$ & AOR $(95 \% \mathrm{CI})^{\mathrm{a}}$ \\
\hline Overall analysis & & & \\
Nonphysician HCP $(n=26,099)$ & $33(0.13)$ & $1.50(0.88-2.57)$ & $1.43(0.82-2.50)$ \\
General population $(n=26,099)$ & $22(0.08)$ & 1.00 & 1.00 \\
\hline Stratified analysis & & & \\
Age $<35$ years & & $2.00(0.81-4.96)$ & $1.71(0.68-4.35)$ \\
$\quad$ Nonphysician HCP & $7(0.09)$ & 1.00 & 1.00 \\
$\quad$ General population & $19(0.04)$ & $1.27(0.64-2.49)$ & $1.29(0.64-2.59)$ \\
Age 35-64 years & $15(0.15)$ & 1.00 & 1.00 \\
$\quad$ Nonphysician HCP & & - & - \\
$\quad$ General population & - & 1.00 & 1.00 \\
Age $\geq 65$ years & & $1.50(0.25-8.98)$ & $1.50(0.25-8.98)$ \\
$\quad$ Nonphysician HCP & & 1.00 & 1.00 \\
$\quad$ General population & $3(0.04)$ & $1.50(0.85-2.64)$ & $1.42(0.79-2.56)$ \\
Male & $2(0.03)$ & 1.00 & 1.00 \\
$\quad$ Nonphysician HCP & & & \\
$\quad$ General population & $30(0.17)$ & $20(0.11)$ &
\end{tabular}

CI, confidence interval; HCP, healthcare providers; VV, varicose vein; OR, odds ratio; AOR, adjusted odds ratio; DVT, deep vein thrombosis. ${ }^{\text {a }}$ Adjusted for DVT history.

tion: 0.12 vs. $0.11 \%$; nonphysician HCP vs. the general population: 0.05 vs. $0.03 \%)$.

During the period of 2007-2011, physicians and nonphysician HCP had a cumulative VV risk incidence of $0.12 \%$ (34/28,844; Table 2) and 0.13\% (33/26,099; Table 3), respectively. The cumulative VV incidence in the general population was $0.13 \%(37 / 28,844)$. Based on conditional logistic regression with adjustment for DVT history, physicians did not have a higher VV risk than the general population (adjusted odds ratio [AOR] 0.86; 95\% CI 0.53-1.40) (Table 2). Stratified analysis by age and sex also showed no significant difference. Nonphysician HCP also did not have a higher risk than the general population (AOR 1.43; 95\% CI 0.82-2.50) in the overall analysis or the stratified analysis (Table 3 ).

Based on an unconditional logistic regression with adjustment for age, sex, and DVT history, physicians did not have a higher VV risk than nonphysician HCP (AOR 0.80 ; $95 \%$ CI $0.43-1.51$ ) (Table 4 ). In the stratified analysis for sex, female physicians had a significantly lower VV risk than female nonphysician HCP (AOR 0.22; 95\% CI $0.05-0.94$ ) (Table 4). Surgery had the highest incidence $(0.22 \%)$ while pediatrics and emergency medicine had the lowest incidence $(0 \%)$ of VV risk among physician specialists; however, the difference was not significant (all $p$ values $>0.05$ ) (Table 5).

\section{Discussion}

In this study physicians and nonphysician HCP had low cumulative VV risk incidences of 0.12 and $0.13 \%$ in Taiwan during the 5 -year period, respectively. The cumulative VV incidence in the general population was $0.13 \%$, indicating that physicians and nonphysician HCP did not have a higher VV risk than the general population. Equally important, there was also no significant difference in VV risk among physicians, nonphysician HCP, and physician specialists.

In this study, physicians in Taiwan did not have a higher VV risk than nonphysician HCP or the general population despite having long work hours. The probable explanation for this could be that physicians have better medical knowledge of how to prevent VV [16, 19, $20]$. The $0.05 \%$ incidence of $\mathrm{VV}$ among female physicians seemed to indicate the risk of VV is different be- 
Table 4. Comparison of the VV risk between physicians and nonphysician HCP by unconditional logistic regression

\begin{tabular}{llll}
\hline & $n(\%)$ & OR $(95 \% \mathrm{CI})$ & AOR $(95 \% \mathrm{CI})^{\mathrm{a}}$ \\
\hline Overall analysis & & & \\
Physicians $n=28,844)$ & $34(0.12)$ & $0.93(0.58-1.51)$ & $0.80(0.43-1.51)$ \\
Nonphysician HCP $(n=26,099)$ & $33(0.13)$ & 1.00 & 1.00 \\
\hline Stratified analysis & & & \\
Age $<35$ years & & $0.62(0.14-2.75)$ & $0.90(0.18-4.36)$ \\
$\quad$ Physicians & $2(0.06)$ & 1.00 & 1.00 \\
$\quad$ Nonphysician HCP & $14(0.09)$ & $0.65(0.36-1.16)$ & $0.75(0.37-1.51)$ \\
Age 35-64 years & $28(0.12)$ & 1.00 & 1.00 \\
$\quad$ Physicians & $19(0.18)$ & - & - \\
$\quad$ Nonphysician HCP & $4(0.22)$ & 1.00 & 1.00 \\
Age $\geq 65$ years & $0(0.00)$ & $3.44(1.05-11.23)^{\mathrm{a}}$ & $2.28(0.66-7.89)$ \\
$\quad$ Physicians & $32(0.13)$ & 1.00 & 1.00 \\
$\quad$ Nonphysician HCP & $3(0.04)$ & $0.30(0.07-1.25)$ & $0.22(0.05-0.94)^{\mathrm{b}}$ \\
Male & $2(0.05)$ & 1.00 & 1.00 \\
$\quad$ Physicians & $30(0.17)$ & & \\
$\quad$ Nonphysician HCP & & & \\
Female & & & \\
$\quad$ Physicians & Nonphysician HCP & &
\end{tabular}

AOR, adjusted odds ratio; OR, odds ratio; $\mathrm{CI}$, confidence interval; $\mathrm{HCP}$, healthcare providers; VV, varicose vein; DVT, deep venous thrombosis. ${ }^{a}$ Adjusted for age, gender, and DVT history. ${ }^{\mathrm{b}} p<0.05$.

Table 5. Comparison of the VV risk among physician specialists by unconditional logistic regression

\begin{tabular}{llll}
\hline Specialty & $n(\%)$ & OR $(95 \% \mathrm{CI})$ & AOR $(95 \% \mathrm{CI})^{\mathrm{a}}$ \\
\hline Surgery $(n=4,071)$ & $9(0.22)$ & $2.33(0.90-6.05)$ & $1.95(0.73-5.18)$ \\
Internal medicine $(n=6,091)$ & $2(0.03)$ & $0.35(0.07-1.63)$ & $0.34(0.07-1.61)$ \\
Pediatrics $(n=2,769)$ & $0(0.00)$ & - & - \\
Ob/gyn $(n=1,969)$ & $3(0.15)$ & $1.61(0.43-6.06)$ & $1.64(0.43-6.24)$ \\
Emergency medicine $(n=479)$ & $0(0.00)$ & - & - \\
Family medicine $(n=2,564)$ & $5(0.20)$ & $2.06(0.67-6.30)$ & $1.92(0.61-6.00)$ \\
Dual specialists $(n=4,071)$ & $7(0.17)$ & $3.00(1.09-8.27)$ & $2.65(0.93-7.53)$ \\
Others $(n=8,434)$ & $8(0.09)$ & 1.00 & 1.00
\end{tabular}

AOR, adjusted odds ratio; OR, odds ratio; CI, confidence interval; VV, varicose vein; Ob/gyn, obstetrics and gynecology; DVT, deep venous thrombosis. ${ }^{a}$ Adjusted for age, gender, and DVT history.

tween physicians and nonphysician HCP depending on the gender. It seems that female physicians have a lower risk of VV (AOR 0.22; 95\% CI 0.05-0.94), which might have an association with the shorter standing time of female physicians compared to nonphysician $\mathrm{HCP}$. As a fact, the incidence of VV in female physicians is $0.05 \%$ and in nonphysician HCP it is $0.17 \%$. In the contrast, male physicians had a trend of a higher risk of VV than male nonphysician HCP (AOR 2.28; 95\% CI 0.66-7.89).

The strength of this study is that it provided cumulative incidence of VV risk among physicians and nonphysician HCP that was more specific than a previous study in Austria which reported that chronic venous diseases 
were present in a total of 70 general hospital employees (34\%), predominantly among women [21]. However, that study included all chronic venous diseases and not only VV and it did not depict the individual results of physicians or comparisons with other populations [21]. Our study used the diagnosis made by physicians as the outcome measurement, which was also more objective than the questionnaire used in the abovementioned study.

The limitations of this study include the nonavailability of detailed information regarding standing and walking hours, family history, body mass index, surgery of the lower limbs, and parity, which might have confounded the results. Secondly, the follow-up period of 5 years was short. Further studies including detailed information, a longer follow-up period, and more patients are warranted.

\section{Conclusion}

In this study, the incidences of VV in physicians, nonphysician HCP, and the general population were low and comparable. There was also no significant difference in VV risk among physician specialists.

\section{Acknowledgments}

This study was supported by grant CMFHR10583 from the Chi-Mei Medical Center, and it was based in part on data from the NHI Research Database provided by the Bureau of National Health Insurance, Department of Health, and managed by National Health Research Institutes.

\section{Disclosure Statement}

The authors declare no conflicts of interest.

\section{References}

1 Bergan JJ, Schmid-Schönbein GW, Smith PD, et al: Chronic venous disease. N Engl J Med 2006;355:488-498.

2 Tabatabaeifar S, Frost P, Andersen JH, et al: Varicose veins in the lower extremities in relation to occupational mechanical exposures: a longitudinal study. Occup Environ Med 2015;72:330-337.

3 Campolmi P, Cannarozzo G, Dragoni F, et al: Efficacy of rhodamine light in the treatment of superficial vascular lesions of the face. Med Princ Pract 2016;25:477-482.

4 Brand FN, Dannenberg AL, Abbott RD, et al: The epidemiology of varicose veins: the Framingham Study. Am J Prev Med 1998;4: 96-101.

5 Criqui MH, Jamosmos M, Fronek A, et al: Chronic venous disease in an ethnically diverse population: the San Diego Population Study. Am J Epidemiol 2003;158:448-456.

6 Lee AJ, Evans CJ, Allan PL, et al: Lifestyle factors and the risk of varicose veins: Edinburgh Vein Study. J Clin Epidemiol 2003;56:171179.

7 Fowkes FG, Lee AJ, Evans CJ, et al: Lifestyle risk factors for lower limb venous reflux in the general population: Edinburgh Vein Study. Int J Epidemiol 2001;30:846-852.
8 Laurikka JO, Sisto T, Tarkka MR, et al: Risk indicators for varicose veins in forty- to sixtyyear olds in the Tampere varicose vein study. World J Surg 2002;26:648-651.

9 Chiesa R, Marone EM, Limoni C, et al: Demographic factors and their relationship with the presence of CVI signs in Italy: the 24-cities cohort study. Eur J Vasc Endovasc Surg 2005; 30:674-680.

10 Jawien A: The influence of environmental factors in chronic venous insufficiency. Angiology 2003;54:19-31.

11 Tüchsen F, Hannerz H, Burr H, et al: Prolonged standing at work and hospitalisation due to varicose veins: a 12 year prospective study of the Danish population. Occup Environ Med 2005;62:847-850.

12 Chen CL, Guo HR: Varicose veins in hairdressers and associated risk factors: a crosssectional study. BMC Public Health 2014;14: 885.

13 Onur E, Kurdal AT, Tugrul B, et al: Is genetic screening necessary for determining the possibility of venous thromboembolism in cancer patients? Med Princ Pract 2012;21:160163.

14 Lee YS, Hsu CC, Weng SF, et al: Cancer incidence in physicians: a Taiwan national population-based cohort study. Medicine (Baltimore) 2015;94:e2079.
15 Kuo WY, Huang CC, Weng SF, et al: Higher migraine risk in healthcare professionals than in general population: a nationwide population-based cohort study in Taiwan. J Headache Pain 2015;16:102.

16 Lin HY, Weng SF, Lin HJ, et al: Peptic ulcer disease in healthcare workers: a nationwide population-based cohort study. PLoS One 2015;10:e135456.

17 Chen HF, Lee CH, Chang RE: Workload of attending physicians at an academic center in Taiwan. J Chin Med Assoc 2010;73:425-430.

18 National Health Research Institutes: National Health Insurance Research Database, Taiwan. http://nhird.nhri.org.tw/en/index.htm (accessed December 13, 2015).

19 Chen YT, Huang CC, Weng SF, et al: Acute myocardial infarction: a comparison of the risk between physicians and the general population. Biomed Res Int 2015;2015:904328.

20 Chen MH, Weng SF, Hsu CC, et al: Urolithiasis risk: a comparison between healthcare providers and the general population. BMC Health Serv Res 2016;16:273.

21 Ziegler S, Eckhardt G, Stöger R, et al: High prevalence of chronic venous disease in hospital employees. Wien Klin Wochenschr 2003;115:575-579. 